\title{
Editorial da Direção
}

\author{
Ética e Prescrição
}

José Augusto Simões*

Para uma correta prescrição reúnem-se o saber e a arte médicas. O médico prescritor segue processos de pensamento racionais e intuitivos para solidificar a sua recomendação terapêutica. O saber provém do conhecimento da evidência científica, construída a partir de rigorosa metodologia e, por isso, capaz de gerar graus de recomendação. A arte engloba a empatia do médico com o paciente, o respeito pelas suas crenças e particularidades, a preocupação com a informação a ser-lhe fornecida, a capacidade para garantir a sua adesão ao tratamento e o desejo de contribuir para a satisfação e qualidade de vida do paciente. ${ }^{1}$

A ética deve estar presente em ambos os aspetos. Para garantir um saber atualizado, o profissional tem o dever ético de manter uma educação médica contínua, para estar ciente dos avanços de uma ciência mutável e permanentemente atualizada por novas evidências. Não é ético desconhecer medidas que possam reduzir significativamente a morbidade e mortalidade dos pacientes. A arte dos cuidados reflete-se no compromisso subjetivo de garantir que os procedimentos atingem os objetivos terapêuticos pretendidos e sejam satisfatórios para os pacientes. ${ }^{1}$

É ética a elaboração de Normas de Orientação Clínica, e no atual contexto de crise financeira é mesmo desejável que tal aconteça, em conjunto com a elaboração de protocolos para o uso racional e custo efetivo de novos medicamentos.

No entanto, em todos os protocolos ou normas de orientação clínica, sendo a independência e a responsabilidade na prescrição inseparáveis da boa prática clínica, o direito à exceção, devidamente fundamentada, deve estar contemplado. ${ }^{2}$

Qualquer norma de orientação clínica irá definir o ponto de referência para o pensamento sobre um determinado tema. Em geral, há pouca orientação ética para os profissionais de saúde na tomada de decisões sobre a alocação de recursos. As orientações emitidas pelo General Medical Council, no Reino Unido, reconhecem que um médico deve considerar as necessidades de seus pacientes individualmente, ao mesmo tempo, tendo em conta que o tratamento para um paciente em particular pode ter impacto sobre a disponibilidade de tratamento para outros pacientes. ${ }^{3}$

\footnotetext{
Médico de Família na Unidade de Saúde Familiar Marquês de Marialva - Cantanhede. 
Ao decidir a priorização dos indivíduos de um recurso limitado, os médicos devem ter em conta os três deveres éticos dos cuidados de saúde (proteger a vida e a saúde, respeitar a autonomia e tratar com justiça). Em muitos casos, esta avaliação dará prioridade à necessidade de proteger a vida e a saúde, para que aqueles cujas necessidades em saúde sejam maiores ou mais urgentes, pela avaliação clínica, sejam prioritários. ${ }^{3}$

Os pacientes devem poder confiar nos médicos as suas vidas e bem-estar. Para justificar essa confiança em nós, como profissão temos o dever de manter um bom padrão de prática de cuidados de qualidade e mostrar respeito pela vida humana.

Os conflitos podem surgir quando os médicos são chamados a tomar decisões sobre o uso dos recursos e sobre o cuidado aos pacientes, quando as necessidades de cada paciente e as necessidades de uma população de pacientes não podem ambas ser cumpridas integralmente. Dilemas deste tipo não têm uma solução simples. Ao tomar tais decisões, os médicos devem ter em conta as prioridades definidas pelas autoridades políticas e as do Serviço Nacional de Saúde e/ou as da sua entidade empregadora ou de financiamento. Mas também devem ter claro qual é o seu próprio papel. Como clínicos, os médicos devem ter no cuidado dos seus pacientes a sua primeira preocupação mas, tendo em conta os efeitos das suas decisões sobre os recursos e opções disponíveis para outros pacientes. Como gestores, os médicos devem alocar recursos da maneira que melhor serve os interesses de uma comunidade ou população de pacientes. Em ambos os papéis, os médicos devem usar as evidências da investigação e de auditorias para fazer a melhor utilização possivel dos recursos disponiveis. ${ }^{3}$

Caso existam Normas de Orientação Clínica, publicadas pela autoridade competente, em Portugal a Direção Geral de Saúde em colaboração com a Ordem dos Médicos, é esperado que os profissionais de saúde as tenham em consideração no exercício da sua avaliação clínica. No entanto, as normas de orientação clínica não substituem a responsabilidade individual dos médicos para tomarem as decisões apropriadas de acordo com as circunstâncias de cada paciente.

É verdade que o Serviço Nacional de Saúde tem o dever de fornecer cuidados de saúde. Mas isso não é e, porque os recursos são finitos, não pode ser, um dever de disponibilizar todos os tratamentos possíveis em todas as circunstâncias. 


\section{Referências Bibliográficas}

1. Wannmacher, L. A ética do medicamento: múltiplos cenários. OMS. Uso racional de medicamentos: Temas selecionados. 2007; 4 (8).

2. Conselho Nacional de Ética para as Ciências da Vida. Parecer 64/CNEV/2012. Parecer sobre um Modelo de Deliberação para Financiamento do Custo dos Medicamentos. Disponível em: http://www.cnecv.pt/admin/files/data/ docs/1348745574_Parecer\%2064_2012\%20CNECV\%20Medicamentos\%20 SNS.pdf.

3. Johnston, C. Slowthe, A. Ethical Considerations. UK Clinical Ethics Network. 2004 Disponivel em: http://www.ukcen.net/uploads/docs/ethical_issues/resource.pdf.

José Augusto Simões,

Presidente da Direção da ADSO 